\title{
Interaction Skills via Spontaneous Speech Sample Analysis: 2- to 5-Year-Old Children with and without Language Impairment
}

\author{
Dongsun Yim, Wonjeong Park, Seonghye Cheon, Yeo-Jin Lee, Jiyeon Lee \\ Department of Communication Disorders, Ewha Womans University, Seoul, Korea
}

Correspondence: Dongsun Yim, $\mathrm{PhD}$ Department of Communication Disorders, Ewha Womans University, 52 Ewhayeodae-gil, Seodaemun-gu, Seoul 03760, Korea Tel: $+82-2-3277-6720$

Fax: +82-2-3277-2122

E-mail: sunyim@ewha.ac.kr

Received: April 13, 2015

Revised: May 7, 2015

Accepted: May 17, 2015

This work was supported by the Korean government (Ministry of Science, ICT and Future Planning) in 2013 (NRF-2013R1A2A2A03068010).

\begin{abstract}
Objectives: Standardized tests and spontaneous speech sample analysis have been used to measure children's language abilities. However, standardized tests alone cannot provide complete information on each child's interaction skills. To obtain specific performance on interaction skills, spontaneous speech sample analysis is essential in clinical situations. Nevertheless, there is no standardized norm in spontaneous speech sample analysis. Thus, this study is designed to investigate performance in typically developing children (TD) in different age groups by analyzing spontaneous speech samples of four subtypes (the number of utterances, initiations, responses, and turn-takings), compared to those of children with language delay (LD). Methods: A total of 131 children ages 2-5 participated in this study. Spontaneous speech samples were collected during three different structured play settings of 25 minutes each and analyzed for interaction skills. Results: The results are as follows. In the TD group, the number of utterances, responses, and turn-takings increased with age, but there was no significant difference in the number of conversation initiations. There was a significant difference in the number of utterances, conversation initiations, responses, and turn-takings between TD and LD. Conclusion: Results suggest that children's spontaneous speech is representative of their language development and can be an effective measure in screening for children at risk of language delay.
\end{abstract}

Keywords: Analysis of spontaneous speech, Typically developing children, Children with language delay, Interaction skills
의사소통은 사람 간의 생각, 의견, 감정을 교류하는 것으로 타인 과의 의사소통 과정을 통한 아동의 언어 및 인지 발달은 사회 구성 원의 일원으로 성장하는 것에 중요한 역할을 하게 된다(Hegde, 1995; $\mathrm{Kim}, 2002)$. 하지만 정상적으로 언어발달이 이루어지지 못할 경우 아동은 사회적 존재로서 성장해 나가는 것에 어려움을 겪을 수 있 다. 때문에 아동의 언어발달 현행 수준과 발달적 적절성을 파악하 는 것은 매우 중요하다. 임상에서는 아동 언어발달 수준을 진단하 기 위해 주로 표준화 검사와 더불어 자발화 분석을 실시한다. 표준 화된 검사는 정적인 상황에서 아동의 언어발달 정도에 대한 검사 가 이루어짐으로써 아동의 언어적 지식을 평가할 수 있다. 또한 검 사 시간상의 효율성을 추구할 수 있으며, 자료의 수집이 용이하고 언어 측정에 대한 신뢰도를 향상시킬 수 있다는 장점이 있다. 또한
반복적인 검사의 실시가 가능하며, 검사 실시와 분석이 간단하기 때문에 진단 및 평가 과정에서 유용하게 사용된다(Kim, Hong, \& $\mathrm{Kim}, 2009)$. 하지만 표준화된 검사상에서 발생한 아동 발화는 아 동의 실제 언어지식을 과소평가할 수 있으며, 대화 기술에 대한 정 보를 충분히 제공하지 못한다. 따라서 실제적인 언어 사용에 대한 정보를 얻기에 어려움이 따르게 된다(Evans \& Craig, 1992; Fujiki \& Brinton, 1987). 표준화 검사의 이러한 단점을 보완하기 위해 아 동의 언어발달 수준을 나타내는 대표적이고 자연스러운 발화의 표 본을 수집한 뒤 이를 검사 목적에 맞게 사용하는 자발화 분석을 실 시한다(Kim, 2002). 이는 아동이 심리적으로 가장 편안하고, 일상 적인 상황에서 이루어짐으로써 자연스런 상황에서 실제로 아동이 언어를 어떻게 사용하고 있는지를 체계적으로 진단할 수 있다. 때 
문에 임상에서 자발화 평가는 아동 언어발달의 현행 수준 및 강점과 약점을 나타내 주는 평가 도구로써 역할을 한다(Price, Hendricks, \& Cook, 2010). 이러한 측면은 구조화되지 않은 상황에서 나타나 는 아동의 자연스러운 발화가 일반 아동과 단순언어장애 아동을 구분해 주는 것에 도움을 줄 수 있다는 기존 연구를 통해 밝혀져 왔다(Fey, 1986; Miller \& Chapman, 1981). 특히 자발화 평가는 표 현 언어의 진단에 중요하며(Lee \& Kim, 1999), 발화의 양적 분석뿐 아니라 질적 분석도 가능하다는 장점이 있다(Miller, 1991). 이렇게 도출된 자발화 분석 결과는 아동의 언어발달 수준의 진단은 물론 (Dunn, Flax, Sliwinski, \& Aram, 1996), 중재 계획에 반영됨으로써 개별 아동에 적절한 목표를 수립하는 것에도 도움을 줄 수 있다 (Blau, 1984).

아동의 자발화 샘플을 얻게 되면 연구자 및 임상가는 자신의 목 적에 따라 크게 의미, 구문 화용론적 측면의 분석을 실시하게 된다 (Kim, 2002). 먼저 의미론적 측면에서의 표현어휘발달 및 어휘다양 도 수준을 평가할 수 있다. 또한 구문론적인 측면에서는 형태소와 낱말의 평균발화길이(mean length of utterance, MLU) 및 문법형 태소의 다양성과 적절성을 질적으로 분석할 수 있다(Brown, 1973).

자발화 평가를 통해 어휘 및 구문적 측면과 같은 양적 분석이 주 로 실시되지만 질적 측면에 관한 분석도 가능케 한다. 구조화된 검 사를 통해서는 아동의 실제 언어 능력을 과소평가하기 쉬우며 표 준화 검사만으로는 평가가 어려운 측면이 있다. 표준화 검사만으로 평가가 어려운 아동 언어적 측면에 관한 정보를 얻기 위해서는 자 발화 분석을 통하여 이루어지는 것이 적절하다. 아동의 화용 능력 을 알아보기 위해 자발화 분석을 통하여 의사소통 의도 분석을 실 시할 경우 요구하기, 반응하기, 객관적 언급 등에 관한 정보를 얻을 수 있다. 이밖에도 대화주제에 대한 개시, 반응 및 대화차례 주고받 기의 빈도와 적절성, 대화 개시와 주제 유지와 같은 담화관리 능력 및 상호작용 기술 등을 분석할 수 있다(Dore, 1978; Heo \& Lee, 2012; Hong \& Kim, 2001).

이러한 각각의 자발화 분석 항목은 아동의 언어 발달 수준을 반 영하기 때문에 연령에 따라 언어 평가 지표상의 각종 수치에서 발 달하는 양상을 보인다. 연령이 증가함에 따라 발화의 양은 증가하 며(Lee, 2010), 평균발화길이 또한 길어지는 경향을 보인다(Jung \& Yoon, 2013; Kim, 1997; Klee \& Fitzgerald, 1985; Miller \& Chapman, 1981). 또한 자발화상에 나타나는 연결어미 형태에서도 발달하는 양상을 보이며(Jung, 2013). 요구하기, 반응하기, 언급하기, 진술하 기 등의 의사소통 의도 표현에서도 발달곡선을 그리는 것으로 보 고된다(Hong \& Kim, 2001). 그뿐만 아니라 아동이 대화차례 주고 받기를 습득하고 언어 및 인지 능력이 발달하면서 주제운용 능력
또한 함께 발달해 나가는 것으로 알려졌다(Brinton \& Fujiki, 1984; Pence \& Justice, 2008). 이와 같은 화용 언어 및 상호작용 기술 등의 발달은 의사소통의 주목적인 사회적 존재로서 적절하게 기능하는 것에 영향을 줄 수 있으므로(Conti-Ramsden \& Botting, 2004) 언 어 평가에 있어 간과할 수 없는 측면이라 할 수 있다.

언어발달지체 아동의 경우 또래 일반 아동에 비해 언어발달의 양적-질적 지표에서 낮은 경향성을 나타낸다. 언어발달지체 아동 에게서 가장 두드러지게 드러나는 특성은 낮은 어휘력이다. 이들은 특히 또래에 비해 낮은 표현어휘력을 가지고 있으며(Grinstead et al., 2013; Hewitt, Hammer, Yont, \& Tomblin, 2005; Klee, Stokes, Wong, Fletcher, \& Gavin, 2004; Paul, Hernandez, Taylor, \& Johnson, 1996; Rice et al., 2010), 어휘의 다양성도 부족한 것으로 나타 났다(Klee, 1992; Lee \& Kim, 1999; Redmond, 2004). 대화 상황에 서 낮은 구어적 반응성을 보이는 등(Bishop, Chan, Adams, Hartley, \& Weir, 2000) 전반적인 양적 수치에서 낮은 수행력을 가진 것 으로 알려져 있다. 또한, 언어발달지체 아동은 화용적 측면에서도 정상 언어발달 아동과 다른 패턴을 보인다. 언어발달지체 아동은 일반 아동에 비해 전체적인 의사소통 빈도와 의사소통 기능이 낮 게 나타났다(Cho \& Lee, 2010). 언어발달지체 아동은 대화 상대와 의 발화를 주고받는 대화차례 주고받기, 대화를 시작하고 이를 유 지해 나가는 주제 운용 능력과 같은 상호작용 기술 측면에서도 어 려움을 나타낸다. 때문에 성인과의 상호작용을 시작하거나 지속하 는 기술(Liiva \& Cleave, 2005), 그리고 대화 과정에 적합한 반응을 산출하는 것에서도 어려움을 나타낸다(Fey, 1986; Rescorla, Bascome, Lampard, \& Feeny, 2001).

그러나 자발화 분석의 활용가능성에 대해 이와 다른 주장을 펴 기도 한다. 선행 연구에서는 상호작용 기술 측면에서 일반 아동과 언어발달장애 아동의 대답하기 횟수 평균에 차이가 유의하지 않았 음을 주장하였다(Limber, 1976). 또한 Lee와 Lee (2013)는 18-36개 월 사이의 표언어발달지체 아동의 대화차례 주고받기 특성을 생활 연령과 언어연령을 일치시킨 일반 영유아와 각각 비교하였다. 연구 결과, 표현언어발달지체 집단은 대화차례 빈도 및 비율에서 두 일반 영유아 집단과 유의한 차이를 보이지 않았다. 그러나 이들의 연구 는 구어는 물론 비구어 행동을 모두 측정하였기 때문이며, 구어 결 과만을 보았을 때에는 표현언어발달지체 영유아가 생활연령 일치 집단에 비해 적은 대화차례 빈도를 보였다. 대화차례 개시에서는 집 단 간에 유의한 차이가 없었으나 구어를 사용한 대화차례 유지에 서는 생활연령 일치 집단에 비해서 유의하게 부족한 수행을 보였다. 앞선 연구 결과로 미루어 볼 때 언어발달지체 아동과 일반 아동, 두 집단에서 나타나는 자발화상의 특성을 보고한 기존의 연구를 
통해 어휘 및 구문적 지연 및 발달적 차이에 대해 분명히 밝혀져 있 으나, 여전히 대화 개시, 유지, 대화차례 주고받기 등의 상호작용 기 술 측면의 능력 차이에 대해서는 상이한 의견을 보이고 있다. 하지 만 상호작용 기술의 지연은 아동의 또래 및 사회적 관계 형성과 학 업 성취 등에 영향을 미치기 때문에(Conti-Ramsden \& Botting, 2004; Owens, 2004) 언어발달지체 아동의 중재 과정에 반드시 고 려해야 할 부분이다. 하지만 현재 언어치료 현장에서는 언어발달지 체 아동의 중재에 주로 언어의 의미적, 구문적 측면에 초점을 맞추 고 있으며, 아동의 상호작용 기술을 평가 및 중재하는 것은 규준의 부재, 개념의 불명확성 등을 이유로 간과되는 경향이 있다. 따라서 임상에서 상호작용 기술을 언어발달지체 아동에 중재하기 위한 이 론적 기초가 필요한 상황이다. 하지만 아동의 상호작용 기술 측면 에 대해 이루어진 연구에서 도출된 결과를 해당 집단의 아동에 일 반화시켜 적용하기에는 다소 적은 아동을 대상으로 연구가 이루어 졌다는 제한점이 따른다. 따라서 본 연구에서는 대화차례 주고받 기 및 주제운용 능력을 포괄하는 상호작용 기술, 세부적으로는 발 화 수, 대화차례 개시 횟수, 반응 횟수, 대화차례 주고받기 횟수가 정상 언어발달 아동에서 연령별로 어떤 양상을 나타내는지 알아보 고, 일반 아동 집단과 언어발달지체 집단 간 차이가 나타나는지에 대해 조사하는 것을 목적으로 하였다. 이를 통해 화용적 측면에서 의 아동 언어발달 특성을 살펴보고, 언어발달지체 아동을 선별하 는 방법으로서 자발화 분석 결과 적용 가능성에 대해 모색해 보고 자 한다. 구체적인 연구 문제는 다음과 같다.

1) 일반 아동 집단의 자발화 분석 결과인 발화 수, 대화차례 개시 횟수, 반응 횟수, 대화차례 주고받기 횟수에서 연령에 따른 차이가 나타나는가?

2) 자발화 분석 결과인 발화 수, 대화차례 개시 횟수, 반응 횟수, 대화차례 주고받기 횟수에서 일반 아동 집단과 언어발달지체 아동 집단 간 차이가 나타나는가?

\section{연구 방법}

\section{연구대상}

본 연구는 서울 및 수도권, 충청도에 거주하는 생활연령 만 2-5

Table 1. Participants' characteristics in TD group

\begin{tabular}{lcccc}
\hline & Age2 (N=29) & Age3 (N=30) & Age4 (N=30) & Age5 ( $\mathrm{N}=30)$ \\
\hline Gender (M:F) & $17: 12$ & $18: 12$ & $10: 20$ & $21: 09$ \\
Age (mo) & $28.03(2.67)$ & $42.10(3.32)$ & $54.07(3.45)$ & $66.30(3.68)$ \\
\hline
\end{tabular}

Values are presented as number or mean (SD).

$\mathrm{TD}=$ children with typical development.
세 남녀 아동 총 131 명(정상 집단 남 66 명, 여 53 명, 언어발달지체 아 동 집단 남 10 명, 여 2 명)을 대상으로 하였다. 정상발달 아동의 대상 자 선정 기준은 다음과 같다. (1) 생활연령 만 2-5세 남녀 아동, (2) 수용 어휘력 검사 결과 $10 \%$ ile 이상, (3) 어절에 의한 평균발화길이 (MLU-c) -2 SD 이상, (4) 신체·인지 발달 문제로 인하여 진단받은 적이 없는 아동, (5) 한국어를 구사하는 단일언어 아동이다. 언어발 달지체 아동의 대상자 선정 기준은 (1) 생활연령 만 2-5세 남.녀 아 동, (2) 수용 어휘력 검사 결과 $10 \%$ ile 미만, (3) 어절에 의한 평균발 화길이(MLU-c) -2 SD 미만, (4) 신체·인지 발달 문제로 인하여 진단 받은 적이 없는 아동, (5) 한국어를 구사하는 단일언어 아동이다. 대 상자 선정 과정에서 심각한 조음상의 문제로 인하여 발화를 전사 하여 분석하기 어려운 경우 전사 및 분석이 어려워 제외되었다. 각 연령별 정상발달 아동에 대한 대상자 정보는 Table 1 에 제시되어 있 다. 또한 집단 간 비교를 위한 정상발달 아동과 언어발달지체 아동 집단 각각의 대상자 정보는 Table 2에 제시되어 있다. 집단 간 비교 는 언어발달지체 아동과 월령 단위의 생활연령이 유사하거나 같은 정상발달 아동 각 12 명의 데이터를 무작위로 추출하여 정상발달 아동 집단을 구성한 뒤, 두 집단을 비교하는 방식으로 이루어졌다.

\section{자료수집 절차}

각각의 아동에 대한 자발화 수집은 연구원이 직접 아동의 교육 기관 혹은 가정에 방문하여 진행되었으며 교육기관 혹은 가정 내에 서 소음이 가장 적고, 다른 장난감으로부터 자발화 수집 절차가 방 해받지 않는 환경에서 이루어졌다. 연구원과 아동이 1:1로 빈 교실 에 앉아 놀이를 진행하는 과정을 통해 아동의 자발화가 스마트폰 (Samsung Galaxy Note 2)을 통해서 녹음되었다. 자료수집을 위한 놀이 상황은 총 3 가지로 기차놀이, 의사놀이, 소꿉놀이였다. 장난 감의 종류가 아동의 발화 정도에 영향을 주지 않도록 모든 아동은 연구자가 준비한 장난감만을 사용하여 놀이에 참여하였으며 아동 이 3 가지 놀이에 모두 참여하지 않는 경우 데이터에서 제외시켰다. 각각의 놀이를 약 10 분씩 총 30 분가량 녹음함으로써 자발화 수집

Table 2. Participants' characteristics by subgroup

\begin{tabular}{lcc}
\hline & TD group (N=12) & LD group (N=12) \\
\hline Gender (M:F) & $6: 6$ & $10: 2$ \\
Age (mo) & $46(11.53)$ & $45.75(11.34)$ \\
Age2 & 1 & 1 \\
Age3 & 7 & 7 \\
Age4 & 2 & 2 \\
Age5 & 2 & 2 \\
\hline
\end{tabular}

Values are presented as number or mean (SD).

$\mathrm{TD}=$ children with typical development; $\mathrm{LD}=$ children with language delay. 
Table 3. Performance on spontaneous speech sample analysis by conversation partners

\begin{tabular}{lccccccccc}
\hline & $\mathrm{R} 1(\mathrm{~N}=30)$ & $\mathrm{R} 2(\mathrm{~N}=28)$ & $\mathrm{R} 3(\mathrm{~N}=18)$ & $\mathrm{R} 4(\mathrm{~N}=15)$ & $\mathrm{R} 5(\mathrm{~N}=22)$ & $\mathrm{R} 6(\mathrm{~N}=26)$ & $\mathrm{R} 7(\mathrm{~N}=33)$ & $\mathrm{R} 8(\mathrm{~N}=24)$ & $F$ \\
\hline Number of utterances & $148.83(69.07)$ & $170.36(99.04)$ & $152.33(75.28)$ & $142.87(81.40)$ & $115.23(61.02)$ & $138.04(84.31)$ & $150.67(93.31)$ & $146.04(79.60)$ & .862 \\
Number of initiations & $21.03(13.56)$ & $38.14(29.69)$ & $28.22(19.57)$ & $27.47(21.59)$ & $26.36(17.53)$ & $34.27(28.93)$ & $26.33(21.62)$ & $38.63(29.73)$ & 1.900 \\
Number of responses & $127.80(63.82)$ & $132.21(78.03)$ & $124.11(63.90)$ & $115.47(63.04)$ & $88.86(47.69)$ & $103.77(62.10)$ & $124.33(75.68)$ & $107.42(59.57)$ & 1.211 \\
Number of turn-takings & $134.30(62.35)$ & $136.29(82.61)$ & $126.50(61.32)$ & $111.87(60.36)$ & $97.09(48.82)$ & $94.65(53.53)$ & $122.27(77.64)$ & $109.17(55.96)$ & 1.528 \\
\hline
\end{tabular}

Values are presented as mean (SD).

$\mathrm{R}=$ researcher.

이 이루어졌으며, 이후 분석 과정에서 녹음 파일의 전반부 2 분을 제외한 뒤총 25 분으로 편집되었다.

아동의 자발화수집에 중요한 대화 상대자 요인을 통제하기 위하 여 다음과 같은 절차를 거쳐 연구원 교육이 이루어졌다. 먼저, 세 차 례에 걸쳐 실시된 예비 연구를 통해 아동의 반응을 이끌어 내기에 가장 적절하다고 판단되는 자발화 수집 매뉴얼을 작성하여 이를 숙지하도록 하였으며, 이를 통한 자발화 수집 및 분석 시연을 최소 두 차례에 걸쳐 교육받았다. 이후 수도권에 위치한 모 병설유치원 46 명의 아동을 대상으로 하여 진행한 예비 연구를 통하여 선별검 사 및 자발화 수집 과정에 대한 교육이 이루어졌다. 자발화 수집을 위한 매뉴얼의 주요 내용은 Appendix 1에 제시되어 있다. 연구 과 정에서 나타날 수 있는 대화 상대자 요인이 통제되었는지 확인하기 위하여 각각의 연구원별로 아동의 자발화 산출 결과에 대한 통계 분석을 실시하였다. 그 결과 8 인의 연구원 모두 발화 수, 대화차례 개시 횟수, 반응 횟수, 대화차례 주고받기 횟수에서 통계적으로 유 의한 차이를 보이지 않았다. 연구원별 아동의 자발화 산출 결과는 Table 3에 제시되어 있다.

\section{자료전사 및 분석}

녹음된 아동의 발화는 4 주 이내에 전사하고 분석하도록 하였다. 전사된 아동의 발화는 발화 수, 대화차례 개시, 반응, 대화차례 주 고받기로 분석되었다. 각 항목의 정의 및 분석 규준은 Appendix 2 에 제시되어 있다.

아동의 자발화 분석은 실험에 참여하였던 8 인의 연구원에 이루 어진 이후 4 인의 연구원에 의해 2 차 재검토 되었다. 분석은 발화 수, 대화차례 개시 횟수, 반응 횟수, 대화차례 주고받기 횟수 모두 25 분 동안 발생한 총 빈도수로 계산되었다. 전체의 $10 \%$ 에 해당하는 데이 터에 대한 검사자 간 신뢰도 분석 결과는 발화 수에서 $96.53 \%$, 대화 차례 개시 횟수 $86.20 \%$, 반응 횟수 $95.48 \%$, 대화차례 주고받기 횟 수 $91.26 \%$ 로 나타났다.

\section{통계 분석}

모든 통계 분석은 SPSS 19.0을 통하여 이루어졌다. 정상발달 아
동의 연령에 따른 발화 수, 대화차례 개시 횟수, 반응 횟수, 대화차 례 주고받기 횟수 차이 분석에 일원분산분석이 사용되었으며 각 연령집단 간 차이를 알아보기 위해 Bonferroni 사후 검정이 실시되 었다. 일반 아동 집단과 언어발달지체 아동 집단 간 발화 수, 대화차 례 개시 횟수, 반응 횟수, 대화차례 주고받기 횟수 차이를 알아보기 위하여 언어발달지체 아동과 월령을 일치시킨 일반 아동의 검사 결 과를 무작위로 추출하여 집단별 비교가 이루어졌으며, 이에 일원 분산분석이사용되었다.

\section{연구 결과}

\section{일반 아동 집단 내 연령별 상호작용 기술 특성}

연령별로 일반 아동의 발화 수, 대화차례 개시 횟수, 반응 횟수, 대화차례 주고받기 횟수에 차이가 있는지 알아보기 위하여 일원분 산분석을 실시하였다. 그 결과 발화 수 $\left(F_{(3,118)}=4.805, p<.05\right)$, 반응 횟수 $\left(F_{(3,118)}=5.081, p<.05\right)$, 대화차례 주고받기 횟수 $\left(F_{(3,118)}=3.876\right.$, $p<.05)$ 에서는 연령이 높아짐에 따라 빈도수도 유의하게 많아지는 경향을 보였다. 하지만 대화차례 개시 횟수는 연령에 따라 유의한 차 이가 나타나지 않았다 $\left(F_{(3,118)}=1.213, p>.05\right)$. 연령에 따른 자발화 평 가 항목의 기술통계량 및 통계 분석 결과는 Table 4 에 제시되어 있다. 각각의 평가 항목에서 나타난 차이가 어느 연령 집단에서 유의 한지 알아보기 위하여 Bonferroni 사후검정을 실시한 결과, 발화 수 $(p<.05)$, 반응 횟수 $(p<.05)$, 대화차례 주고받기 횟수 $(p<.05)$ 모 두 만 2 세와 만 5 세 간에만 유의한 차이가 나타났으며 이 외 연령에 서는 유의한 차이가 나타나지 않았다( $p>.05)$. 사후분석 결과에 따 른 각 평가 항목별 평균 그래프는 Figure 1에 제시되어 있다.

\section{일반 아동과 언어발달지체 아동의 상호작용 기술 특성 비교}

일반 아동과 언어발달지체 아동의 발화 수, 대화차례 개시 횟수, 반응 횟수, 대화차례 주고받기 횟수에 차이가 있는지 알아보기 위해 일원분산분석을 실시하였다. 그 결과 발화 수 $\left(F_{(1,23)}=6.878, p<.05\right)$, 대화차례 개시 횟수 $\left(F_{(1,23)}=9.274, p<.05\right)$, 반응 횟수 $\left(F_{(1,23)}=5.234\right.$, $p<.05)$, 대화차례 주고받기 횟수 $\left(F_{(1,23)}=2.255, p<.05\right)$ 모두에서 
Table 4. Descriptive statistics and statistical information on spontaneous speech sample analysis by age in TD group

\begin{tabular}{lrrrrr}
\hline & Age2 $(\mathrm{N}=29)$ & Age3 $(\mathrm{N}=30)$ & Age4 $(\mathrm{N}=30)$ & Age5 $(\mathrm{N}=30)$ & $F$ \\
\hline Number of utterances & $135.21(68.31)$ & $155.20(57.55)$ & $179.27(79.61)$ & $200.67(75.05)$ & $4.805^{*}$ \\
Number of initiations & $28.83(19.26)$ & $33.10(20.26)$ & $34.03(24.10)$ & $40.67(31.14)$ & 1.213 \\
Number of responses & $106.38(55.71)$ & $122.10(48.15)$ & $145.23(65.71)$ & $160.00(59.04)$ & $5.081^{*}$ \\
Number of turn-takings & $108.79(52.86)$ & $125.50(51.64)$ & $147.57(63.53)$ & $155.67(65.53)$ & $3.876^{*}$
\end{tabular}

Values are presented as mean (SD).

$\mathrm{TD}=$ children with typical development

${ }^{*} p<.05$.
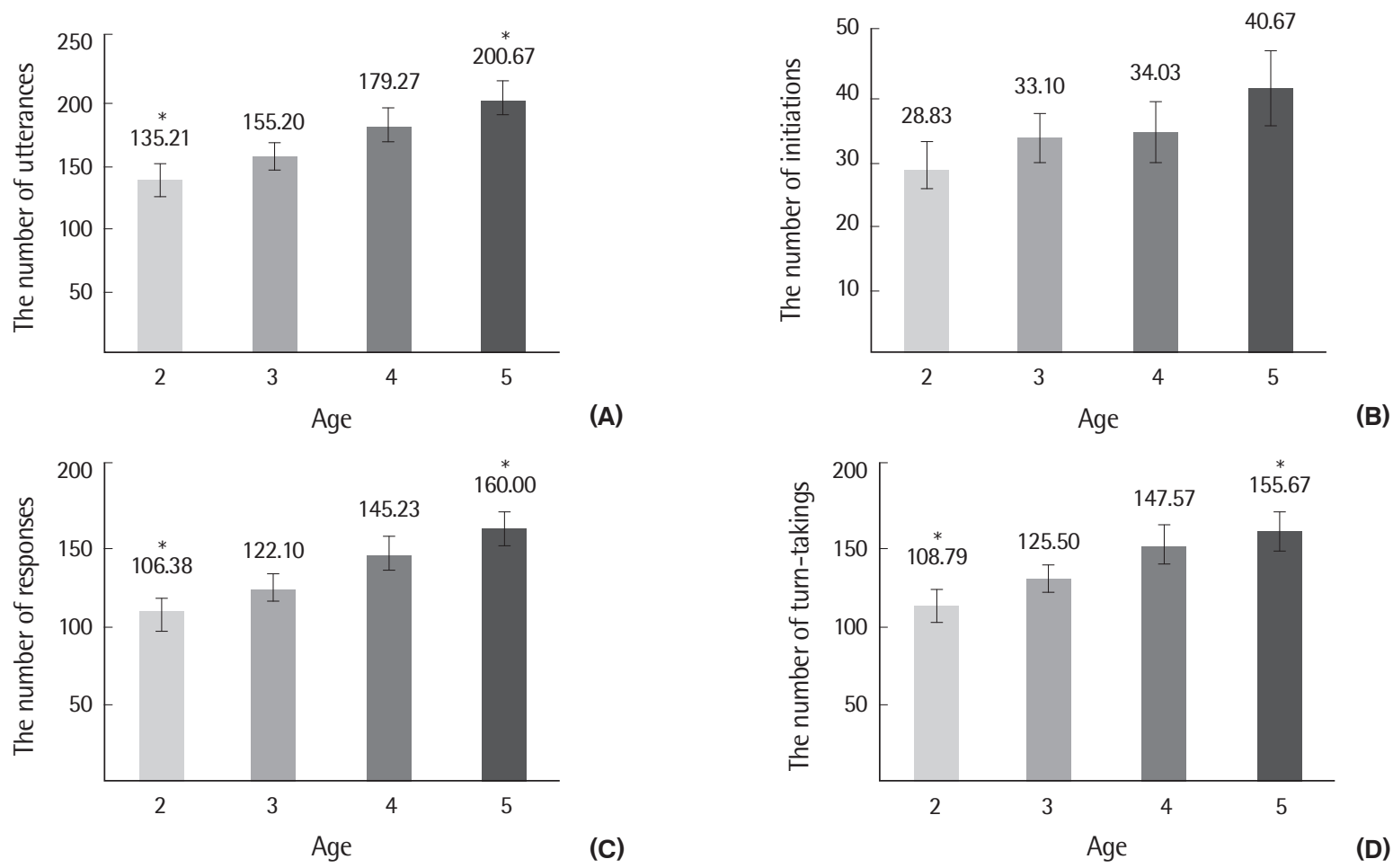

(B)

(A)

(C)

Figure 1. The number of utterances by age. (A) The number of utterances, $(B)$ the number of initiations, (C) the number of responses, and (D) the number of turn-takings. ${ }^{*} p<.05$.

Table 5. Descriptive statistics and statistical information on spontaneous speech sample analysis by subgroup

\begin{tabular}{lrrr}
\hline & $\mathrm{TD}(\mathrm{N}=12)$ & $\mathrm{LD}(\mathrm{N}=12)$ & $F$ \\
\hline Number of utterances & $148.42(64.25)$ & $72.33(77.28)$ & $6.878^{*}$ \\
Number of initiations & $29.00(17.42)$ & $11.08(10.58)$ & $9.274^{*}$ \\
Number of responses & $119.42(55.78)$ & $61.25(68.16)$ & $5.234^{*}$ \\
Number of turn-takings & $121.92(53.95)$ & $64.00(68.91)$ & $2.255^{*}$ \\
\hline
\end{tabular}

Values are presented as mean (SD).

$\mathrm{TD}=$ children with typical development; $\mathrm{LD}=$ children with language delay. ${ }^{*} p<.05$.

집단 간 차이가 유의한 것으로 나타났다. 집단별 자발화 평가 항목 의 기술통계량 및 통계 분석 결과는 Table 5 에 제시되어 있으며, 이 에 대한 그래프는 Figure 2에 제시되어 있다.

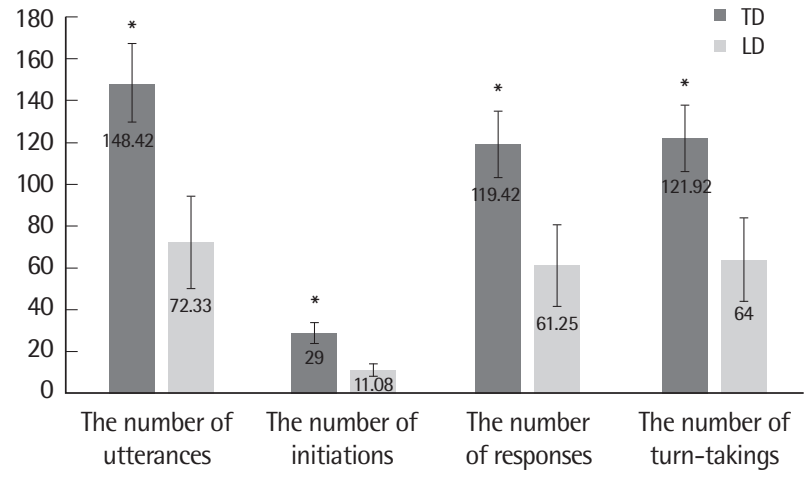

Figure 2. A comparison of spontaneous speech sample analysis by subgroup. $\mathrm{TD}=$ children with typical development; $\mathrm{LD}=$ children with language delay. ${ }^{*} p<.05$. 


\section{논의 및 결론}

본 연구는 자발화 분석 항목으로서의 발화 수, 대화차례 개시 횟 수, 반응 횟수, 대화차례 주고받기 횟수가 일반 아동 집단에서 연령 별로 발달하는 양상을 보이는지, 그리고 각각의 항목에서 언어발 달지체 아동과 일반 아동이 차이를 나타내는지 알아보는 것을 목 적으로 하였다.

먼저, 일반 아동 집단에서 발화 수, 대화차례 개시 횟수, 반응 횟 수, 대화차례 주고받기 횟수가 연령에 따라 어떠한 변화 양상을 보 이는지 알아보기 위해 만 2-5세 아동, 총 119명에 대한 자발화 분석 을 실시하였다. 그 결과 전체 종속변수(발화 수, 대화차례 개시 횟 수, 반응 횟수, 대화차례 주고받기 횟수) 모두에서 연령이 증가함에 따라 각 항목의 수치도 정비례하는 곡선을 나타냈다. 이는 만 2-5세 일반 아동은 상호작용 기술이 전반적으로 발달하는 경향을 나타 낸다는 것을 시사한다. 하지만 대화차례 개시를 제외한 발화 수, 반 응 횟수, 대화차례 주고받기 횟수에서만 연령 간 유의한 차이가 나 타났으며, 세부적으로 이러한 차이는 만 2 세 아동 집단과 만 5 세 아 동 집단 간 유의한 차이에서 기인한 것으로 밝혀졌다. 이는 집단 내 에서 연령 차이가 가장 큰 만 2 세와 만 5 세 집단 아동들의 언어 및 상호작용 기술의 발달 격차가 가장 크게 나타나기 때문에 이러한 영향으로 수행력의 차이 또한 유의하게 나타난 것으로 분석된다.

본 연구의 정상발달 아동 연령별 비교에서 총 네 개의 종속변수 (발화 수, 대화차례 개시 횟수, 반응 횟수, 대화차례 주고받기 횟수) 중, 대화차례 개시 횟수에서만 유의한 차이가 나타나지 않았다. 선 행연구인 Brinton과 Fujiki (1984)에서는 대화 주제 개시 빈도는 아 동이 성장함에 따라 현저하게 줄어든다고 밝혔다. 연령이 높아질 수록 주제 개시 빈도는 줄어드는 경향이 있지만 이에 반해 주제를 유지하는 비율은 높아짐으로써 한 가지 주제로 더 많은 대화를 주 고받기 때문에 상대적으로 주제 개시는 연령이 높아질수록 점차 줄어든다는 것이다. 본 연구에서의 대화차례 개시 횟수가 새로운 주제를 통하여 대화를 시작한 경우를 포함하므로 선행 연구의 주 제 개시 능력과 유사한 것으로 본다면, 본 연구의 대상 연령인 만 2-5세 일반 아동 집단에서 대화 개시 능력은 선행 연구 결과와 같 이 유의한 차이를 나타내지 않았다. 하지만 선행 연구에서는 연령 이 만 5 세에서 만 9 세로 높아짐에도 불구하고 대화차례 개시 횟수 가 거의 유지되는 경향을 보였다면 본 연구에서는 연령이 높아질 수록 점차 대화차례 개시 횟수가 증가하는 경향을 보였다. 이는 본 연구의 대상 연령 아동 집단이 다양한 주제로 대화를 개시하는 능 력이 발달해 가는 시기에 있으나 상대적으로 높은 연령의 아동에 비해 한 가지 주제를 오랫동안 유지하여 대화를 유지하기에 언어.
인지적으로 발달이 미숙하기 때문에 이러한 만 2-5세 아동의 특성 을 반영한 것으로 보인다.

자발화 분석 결과에 따른 연령별 차이는 다수의 선행연구를 통 하여 보고되어 왔다. 하지만 대다수의 연구는 주로 구문 및 어휘 측 면에 초점을 맞추어 진행되어 왔으며 발화 수, 대화차례 개시 횟수, 반응 횟수 등 상호작용 기술에 초점을 둔 연구는 소수에 그쳐있는 실정이다. 상호작용 기술 측면에서의 대화차례 주고받기에 대한 연 구는 국내외에서 계속되고 있으나(Adams \& Bishop, 1989; Craig \& Evans, 1989; Lee \& Kim, 2001; Lee \& Lee, 2013; Heo \& Lee, 2012) 이 또한 대부분이 소수의 언어발달지체 아동과 일반 아동의 차이에 초점을 맞추어 이루어져 왔다. 본 연구는 일반 아동 총 119 명의 자 발화 샘플을 대상으로 하여 총 발화 수, 대화차례 개시 횟수, 반응 횟수, 대화차례 주고받기 횟수의 연령별 차이를 다루었다는 점에서 일반 아동의 상호작용 기술상의 특성에 대한 이해를 더하였다는 점에 그 의의를 둘수 있다.

다음으로 일반 아동 집단과 언어발달지체 아동 집단의 발화 수, 대화차례 개시 횟수, 반응 횟수, 대화차례 주고받기 횟수에 대한 차 이를 알아보기 위해 일반 아동 집단에서 연령을 일치시켜 무작위로 선택된 12 명의 자발화 분석 결과와 선별검사 기준에 따라 언어발달 지연으로 판단된 12 명의 자발화 분석 결과, 총 24 명의 자발화 분석 결과를 비교하였다. 그 결과 발화수, 대화차례 개시 횟수, 반응 횟수, 대화차례 주고받기 횟수에서 집단 간 유의한차이가 나타났다.

이미 다수의 선행 연구에서는 언어발달지체 아동과 일반 아동이 발화 길이 및 어휘다양도 등 어휘·구문적 측면에 중점을 두고 집단 간 유의한 차이를 보인다는 것을 밝혀왔다(Grinstead et al., 2013; Hewitta et al., 2005; Johnston, 2001; Klee, 1992; Klee et al., 2004; Lee \& Kim, 1999; Redmond, 2004). 이와 더불어 본 연구 결과를 토 대로 상호작용 기술 측면에 대한 자발화 분석 또한, 단순언어장애 아동과 일반 아동을 선별해 낼 수 있다고 보고한 선행 연구 결과 (Craig \& Washington, 1993; Fujiki \& Brinton, 1987)와 같이, 일반 아동과 언어발달지체 아동의 차이를 보여줄 수 있는 것으로 나타 났다. 한편, 표현 언어발달지체 아동의 대화차례 및 대화 개시 능력 에 대해 연구하였던 선행 연구에서는 표현 언어발달지체 아동과 일 반 아동 간에 유의한 차이가 없음이 보고되었다(Lee \& Lee, 2013). Lee \& Lee (2013)의 연구는 본 연구의 대상자보다 나이가 어린 18-36 개월 영유아를 대상으로 하였기 때문에 분석 대상에 구어는 물론 비구어 의사소통 행동도 포함하여 이러한 차이가 두 연구 결과의 차이를 유발한 것으로 보인다. 그러나 Lee \& Lee (2103)의 연구 결 과에서 구어 의사소통 행동만을 보았을 때에는 본 연구의 결과와 마찬가지로 대화 개시 능력이나 대화를 적절하게 유지하는 능력 모 
두 생활연령이 같은 또래에 비해서는 유의하게 낮았다. 반응 횟수 의 경우, 언어발달지체 아동의 언어적 반응성과 적절한 반응 정도 가 일반 아동 집단과 달리 단순언어장애 아동 집단에게서 저하된 것으로 나타났다는 선행 연구의 결과와 일치하는 것으로 나타났다 (Bishop et al., 2000).

언어발달지체 아동은 중재를 통하여 의미·구문적 능력을 또래 수준으로 향상시킨 이후에도 상호작용 기술의 사용이 적절하게 이 루어지지 못함으로 인해 관계 형성 및 학업 성취에서 어려움을 겪 을 수 있다(Owens, 2004). 따라서 상호작용 기술 측면에서의 발화 수, 대화차례 개시, 반응, 대화차례 주고받기 능력을 고려하여 이를 언어 중재의 진단 및 평가 과정에 반영해야 한다. 때문에 임상에서 는 아동이 가진 상호작용 기술 측면에 초점을 맞추어 이에 대한 개 별 및 집단 중재가 실시되지만 실제적인 아동의 현행 수준을 판단 하거나 상호작용 기술의 중재 효과성에 대해 수치화하여 객관적인 자료로 나타내는 것이 어려운 상황이다. 따라서 본 연구의 결과는 임상에서 아동의 상호작용 기술 능력의 판단하고 이를 중재 과정 에 반영하여 아동의 상호작용 기술 증진을 돕기 위한 기초 자료로 서 사용될 수 있을 것이다.

본 연구의 제한점 및 제언은 다음과 같다. 먼저, 아동의 자발화 샘플 수집이 주 양육자와 같은 친숙한 대화 상대자를 통해 이루어 진 것이 아니라 낮선 검사자를 통해 이루어졌기 때문에 실제 아동 의 언어 능력에 비해 낮은 결과를 나타냈을 가능성이 있다. 또한, 상 호작용 기술에 대한 연령별 비교에서 만 2 세와 만 5 세 아동 집단에 서는 유의한 차이가 나타났으나 이외 집단에서는 차이가 유의하지 않은 것으로 나타났기 때문에 상호작용 기술 내에서 아동의 발달 곡선을 더 명확하게 보여줄 수 있는 종속변수에 대한 후속 연구가 필요할 것이다. 이와 더불어 본 연구에서 사용된 종속변수인 대화 차례 개시와 반응 횟수에 더하여 적절한 대화차례 개시 혹은 적절 한 반응에 대해 구체적으로 살펴봄으로써 담화 관리 측면에서 아 동의 상호작용 기술에 대해 면밀하게 파악할 필요가 있을 것이다.

\section{REFERENCES}

Adams, C., \& Bishop, D. V. (1989). Conversational characteristics of children with semantic-pragmatic disorder. I: exchange structure, turntaking, repairs and cohesion. British Journal of Disorders of Communication, 24, 211-239.

Bishop, D. V. M., Chan, J., Adams, C., Hartley, J., \& Weir, F. (2000). Conversational responsiveness in specific language impairment: evidence of disproportionate pragmatic difficulties in a subset of children. Development and
Psychopathology, 12, 177-199.

Blau, A. F. (1984). Planning goals for intervention: language testing or language sampling? Exceptional Children, 51, 78-79.

Brinton, B., \& Fujiki, M. (1984). Development of topic manipulation skills in discourse. Journal of Speech, Language, and Hearing Research, 27, 350-358.

Brown, R. (1973). A first language: the early stages. Cambridge, MA: Harvard University Press.

Cho, M. R., \& Lee, Y. (2010). Communicative behaviors of toddlers with or without language delay. Korean Journal of Early Childhood Special Education, 10, 31-46.

Conti-Ramsden, G., \& Botting, N. (2004). Social difficulties and victimization in children with SLI at 11 years of age. Journal of Speech, Language, and Hearing Research, 47, 145-161.

Craig, H. K., \& Evans, J. L. (1989). Turn exchange characteristics of SLI children's simultaneous and nonsimultaneous speech. Journal of Speech and Hearing Disorders, 54, 334-347.

Craig, H. K., \& Washington, J. A. (1993). Access behaviors of children with specific language impairment. Journal of Speech, Language, and Hearing Research, 36, 322-337.

Dore, J. (1978). Conditions for the acquisition of speech acts. In I. Markova (Ed.), The social context of language (pp. 87-111). Chichester: Wiley.

Dunn, M., Flax, J., Sliwinski, M., \& Aram, D. (1996). The use of spontaneous language measures as criteria for identifying children with specific language impairment: an attempt to reconcile clinical and research incongruence. Journal of Speech, Language, and Hearing Research, 39, 643-654.

Evans, J. L., \& Craig, H. K. (1992). Language sample collection and analysis: interview compared to freeplay assessment contexts. Journal of Speech, Language, and Hearing Research, 35, 343-353.

Fey, M. E. (1986). Language intervention with young children. San Diego, CA: College-Hill Press.

Fujiki, M., \& Brinton, B. (1987). Elicited imitation revisited: a comparison with spontaneous language production. Language, Speech, and Hearing Services in Schools, 18, 301-311.

Grinstead, J., Baron, A., Vega-Mendoza, M., De la Mora, J., Cantú-Sánchez, M., \& Flores, B. (2013). Tense marking and spontaneous speech measures in Spanish specific language impairment: a discriminant function analysis. Journal of Speech, Language, and Hearing Research, 56, 352-363.

Hegde, M. N. (1995). Introduction to communicative disorders (2nd ed.). Austin, TX: Pro-Ed.

Heo, H. S., \& Lee, Y. (2012). Conversational turn-taking and topic manipula- 
tion skills in conversations of school-age low-achievers in language learning. Korean Journal of Communication Disorders, 17, 66-78.

Hewitt, L. E., Hammer, C. S., Yont, K. M., \& Tomblin, J. B. (2005). Language sampling for kindergarten children with and without SLI: mean length of utterance, IPSYN, and NDW. Journal of Communication Disorders, 38, 197-213.

Hong, K. H., \& Kim, Y. T. (2001). A longitudinal study of the acquisition of communicative intentions. Korean Journal of Communication Disorders, 6 , 17-39.

Johnston, J. R. (2001). An alternate MLU calculation: magnitude and variability of effects. Journal of Speech, Language, and Hearing Research, 44, 156-164.

Jung, B. J. (2013). The relationship of sample sizes and mean length of utterances for typically developing children aged 2 to 4 years. Journal of the Korean Association for Persons with Autism, 13, 39-51.

Jung, Y. H., \& Yoon, M. S. (2013). Mean length of utterance for typically developing children of 2 to 4 years. Korean Journal of Early Childhood Special Education, 13, 55-73.

Kim, Y. T. (1997). Foundation of length of utterance in 2 to 4 year-old children. Korean Journal of Communication Disorders, 2, 5-25.

Kim, Y. T. (2002). Assessment and treatment of language disorders in children. Seoul: Hakjisa.

Kim, Y. T., Hong, G. H., \& Kim, K. H. (2009). Content and reliability analyses of the Receptive and Expressive Vocabulary Test (REVT). Korean Journal of Communication Disorders, 14, 34-45.

Klee, T. (1992). Developmental and diagnostic characteristics of quantitative measures of children's language production. Topics in Language Disorders, $12,28-41$.

Klee, T., \& Fitzgerald, M. D. (1985). The relation between grammatical development and mean length of utterance in morphemes. Journal of Child Language, 12, 251-269.

Klee, T., Stokes, S. F., Wong, A. M. Y., Fletcher, P., \& Gavin, W. J. (2004). Utterance length and lexical diversity in Cantonese-speaking children with and without specific language impairment. Journal of Speech, Language, and Hearing Research, 47, 1396-1410.

Lee, H. J., \& Kim, Y. T. (1999). Measures of utterance length of normal and language-delayed children. Korean Journal of Communication Disorders, 4, 153-166.

Lee, H. J., \& Kim, Y. T. (2001). Turn-taking characteristics of Specific lan- guage impairment and normal children. Korean Journal of Communication Disorders, 6, 293-312.

Lee, H. R. (2010). Development of sentence structures in Korean children age of 3-6 years. Journal of Speech \& Hearing Disorders, 19, 179-192.

Lee, Y., \& Lee, H. J. (2013). Conversational turn-taking of toddlers with language delay. Special Education Research, 12, 357-377.

Liiva, C. A., \& Cleave, P. L. (2005). Roles of initiation and responsiveness in access and participation for children with specific language impairment. Journal of Speech, Language, and Hearing Research, 48, 868-883.

Limber, J. (1976). Unravelling competence, performance and pragmatics in the speech of young children. Journal of Child Language, 3, 309-318.

Miller, J. F. (1991). Quantifying productive language disorders. In Research on child language disorders: a decade of progress (pp. 211-220). Austin, TX: Pro-Ed.

Miller, J. F., \& Chapman, R. S. (1981). The relation between age and mean length of utterance in morphemes. Journal of Speech, Language, and Hearing Research, 24, 154-161.

Owens, R. E. (2004). Language disorders: a functional approach to assessment and intervention (4th ed.). Boston, MA: Allyn and Bacon.

Paul, R., Hernandez, R., Taylor, L., \& Johnson, K. (1996). Narrative development in late talkers: early school age. Journal of Speech, Language, and Hearing Research, 39, 1295-1303.

Pence, K. L., \& Justice, L. M. (2008). Language development from theory to practice. Upper Saddle River, NJ: Prentice Hall.

Pennington, L. (2009). Effects of it takes two to talk-the Hanen Program for parents of preschool children with cerebral palsy: findings from an exploratory study. Journal of Speech, Language, and Hearing Research, 52, 11211138.

Price, L. H., Hendricks, S., \& Cook, C. (2010). Incorporating computer-aided language sample analysis into clinical practice. Language, Speech, and Hearing Services in Schools, 41, 206-222.

Redmond, S. M. (2004). Conversational profiles of children with ADHD, SLI and typical development. Clinical Linguistics \& Phonetics, 18, 107-125.

Rescorla, L., Bascome, A., Lampard, J., \& Feeny, N. (2001). Conversational patterns in late talkers at age 3. Applied Psycholinguistics, 22, 235-251.

Rice, M. L., Smolik, F., Perpich, D., Thompson, T., Rytting, N., \& Blossom, M. (2010). Mean length of utterance levels in 6-month intervals for children 3 to 9 years with and without language impairments. Journal of Speech, Language, and Hearing Research, 53, 333-349. 
Dongsun Yim, et al. • Interaction Skills via Spontaneous Speech Sample Analysis

Appendix 1. Manual for speech sample collection

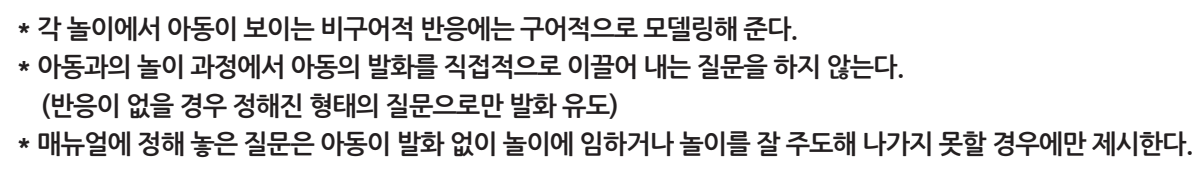

\section{- 블록놀이}

기찻길과 기차, 동물원 장난감을 세팅해 놓은 후, 아동에게 “지금부터 우리 뭐 하고 놀까?” 하고 물어본다. 아동이 대답할 경우 아동의 주도에 따른다. 아동이 주도 하지 못하는 경우 기차놀이를 할 수 있도록 유도한다.

아동이 발화를 시작하지 못하는 경우 “기차 타고 어디 갈 거야?”로 시작한다. 반응이 없을 경우 “동물원에 갈까?”라고 하여 놀이를 시작한다. 아동이 기차를 가지고 동물원을 다니면 연구원은 동물의 역할을 하면서 아동의 발화를 이끌어낸다(예, “안녕, 난 기린이야. 넌 누구니?”, “왜 여기에 왔어?”, "이제 어디에 갈 거야?”).

\section{- 의사놀이}

역할을 정한다. 아동이 스스로 정하지 못하는 경우 연구원은 의사, 아동은 환자로 시작.

연구원이 의사 역할을 맡을 경우, "어디가 아파서 오셨어요?” 하고 물어본 뒤 반응을 유도한다. 반응이 없을 경우 청진기를 대 주고 다시 한 번 증상에 대해 이야기 해 준다.

“그 다음엔 어떻게 하지?" 말하며 의사가 다음 할 행동에 대해 아동이 주도하도록 한다. 아동의 반응이 없을 경우 주사를 놓으며 “어디에 놓아 드릴까요?”로 아동의 반응을 이끌어 낸다. “다 나으셨어요?”라고 질문하여 다 나았을 경우 밴드를 붙여 주고 마무리, 다 낫지 않았다고 할 경우 “그 다음엔 어떻게 하지?”부터 다시 반복 한다. 아동의 반응이 없을 경우, 치료 순서는 청진기 $\rightarrow$ 주사 $\rightarrow$ 약 $\rightarrow$ 밴드 순서로 동일하게 진행된다.

연구원이 환자 역할을 맡을 경우, “아, 배가 아파요”라고 말한다. 아동의 반응이 없을 경우, “선생님, 저 어떻게 해요?” 하고 물어본다. 아동이 진찰을 하면서 말할 경 우, 아동의 주도에 따른다. 아동이 진찰을 하면서 말하지 않을 경우, “선생님 저 많이 아픈가요?” 하고 물어본다. 아동이 장난감을 만지거나 사용하는 경우 “이걸로 뭐 하는 거예요?" 하고 묻는다.

\section{- 소꿉놀이}

아동이 역할을 주면 역할에 따른다. 아동이 역할을 정하지 않고 시작할 경우, “지금부터 우리 뭐 할 거야?” 한 뒤 아동의 주도에 따른다. 놀이 진행은 “그 다음엔 뭐 할 거야?”라는 질문으로 이어나간다. 아동이 놀이 상황에서 대화를 주도해 나갈 경우 부가적인 질문을 하지 않고 아동의 대화에 응하지만, 아동이 대화를 주도하지 못할 경우 상황에 대한 질문을 던진다(예, 아동이 요리를 할 경우에, "지금 뭐 만들고 있어?", “그건 어떻게 만드는 거야?" 아동이 음식을 먹을 경우에, "이게 뭐야?", "어떻게 먹는 거야?" 등).

Appendix 2. Definitions for each part of spontaneous sample analysis

\begin{tabular}{|c|c|}
\hline 평가 항목 & 정의 및 규준 \\
\hline 발화 수 & $\begin{array}{l}\text { Lee와 Kim (2001)에서 제시된 '말차례에서의 발화 구분 원칙’을 기초로 하여 발화를 구분하였다. 따라서 한 문장을 한 발화로 보았으며, } \\
\text { 약 } 5 \text { 초 가량의 시간이 경과하거나 두드러진 운율의 변화, 주제의 변화가 있을 때 발화의 수를 나누었다. }\end{array}$ \\
\hline 대화차례 개시 횟수 & $\begin{array}{l}\text { Lee와 Lee (2013)에서 언급된 대화차례 개시의 정의에 따라 대화차례 개시를 (1) 아동이 새로운 주제로 처음 대화를 시작하는 경우, } \\
\text { 혹은 (2) 3초 이상의 대화 중단이 발생한 이후에 아동이 먼저 대화차례를 시작하는 경우로 보았다. }\end{array}$ \\
\hline 반응 횟수 & $\begin{array}{l}\text { Pennington (2009)에서 기술된 바에 기초하여, 개시에 의해 예측되거나 답변되며, 뒤에 또 다른 반응이 있을 것이라고 예측되지 않는 반응 } \\
\text { (response)과, 대화 개시가 나타나면 그에 답변하는 것으로서 나타나는 것이며 이에 또 뒤따르는 반응을 요구하게 되는 반응 개시(response } \\
\text { initiation)로 나눠진다. 본 논문에서는 앞서 설명된 반응과 반응 개시 모두를 대화차례 개시와 반대되는 “반응의 개념으로 보았다. }\end{array}$ \\
\hline 대화차례 주고받기 횟수 & $\begin{array}{l}\text { 두 명의 발화 상대자가 대화를 이어가는 것을 의미하며 본 논문에서의 대화차례 주고받기는 Lee와 Lee (2013)의 정의에 기초하여, 개별 발화 } \\
\text { 가 맥락에 맞게 개시 또는 반응하는 경우 그리고 해당되는 발화의 앞뒤에 의미적으로 연결되는 상대방의 발화가 이어질 경우 적절한 대화 } \\
\text { 차례로 보았다. }\end{array}$ \\
\hline
\end{tabular}




\section{국문초록}

\section{자발화 분석을 통한 만 2-5세 아동의 상호작용 기술 특성 및 언어발달지체 아동 비교 연구}

임동선 · 박원정 · 천성혜 · 이여진 · 이지연

이화여자대학교 일반대학원 언어병리학과

배경 및 목적: 자발화 분석은 아동의 발화의 의미, 구문 및 화용적 특성을 드러내 주는 검사 방식으로서 언어 수준 진단에 중요한 역할 을 한다. 표준화 검사만으로는 아동의 실제 언어지식을 과소평가할 수 있으며, 상호작용 기술에 대해 충분한 정보를 제공받기 어려우므 로 자발화 분석이 함께 실시되어야 한다. 본 연구에서는 자발화 분석을 통해 일반 아동의 발화 수, 대화차례 개시 횟수, 반응 횟수, 대화 차례 주고받기 횟수가 연령별로 어떤 양상을 나타내는지, 각각의 항목에서 일반 아동 집단과 언어발달지체 아동 집단 간에 차이가 나 타나는지 알아보고자 하였다. 방법: 만 2-5세 남녀 일반 아동 및 언어발달지체 아동 131 명을 대상으로, 25 분간 세 가지 지정된 놀이 상 황에서 자발화를 수집하고 이에 대한 상호작용 기술 분석을 실시하였다. 결과: 일반 아동 집단에서 발화 수, 반응 횟수, 대화차례 주고 받기 횟수는 연령이 높아질수록 유의하게 많아지는 경향을 보였으나, 대화차례 개시 횟수에서는 유의한 차이가 나타나지 않았다. 발화 수, 대화차례 개시 횟수, 반응 횟수, 대화차례 주고받기 횟수 모두에서 일반 아동 집단과 언어발달지체 집단 간 유의한 차이가 나타났다. 논의 및 결론: 자발화 분석을 통하여 아동 상호작용 기술 발달 양상을 볼 수 있으며, 언어발달지체 아동 집단과의 유의한 차이가 있는 것으로 나타났다.

핵심어: 자발화 분석, 일반 아동, 언어발달지체 아동, 상호작용 기술

본 연구는 2013년도 정부(미래창조과학부)의 재원으로 한국연구재단의 지원을 받아 연구되었음(NRF-2013R1A2A2A03068010).

\section{참고문헌}

김영태(2002). 아동언어장애의 진단 및 치료. 서울: 학지사.

김영태(1997). 한국 2-4세 아동의 발화길이에 관한 기초 연구. 언어청각장애연구, 2, 5-25.

김영태, 홍경훈, 김경희(2009). 수용·표현 어휘력 검사(Receptive and Expressive Vocabulary Test: REVT)의 개발연구: 문항개발 및 신뢰도 분석을 중 심으로. 언어청각장애연구, $14,34-45$.

이윤경, 이효주(2013). 표현언어발달지체 영유아의 대화차례 주고받기 특성. 특수교육, 12, 357-377.

이효진, 김영태(2001). 단순언어장애 아동의 대화 말차례 특성. 언어청각장애연구, 6, 293-312.

이희란 (2010). 학령전 아동의 구문표현력 발달에 관한 종단연구. 언어치료연구, 19, 179-192.

이희정, 김영태(1999). 자발화 표본 분석의 정량화를 통한 언어발달지체의 판별 연구: 발화길이를 중심으로. 언어청각장애연구, 4, 153-166.

정부자(2013). 2-4 세 일반아동의 자발화 표본크기와 평균발화길이의 비교. 자폐성장애연구, 13, 39-51.

정윤희, 윤미선(2013). 2, 3,4세 일반 아동의 평균발화길이. 유아특수교육연구, 13, 55-73.

조미라, 이윤경(2010). 언어발달지체 유아와 일반 유아의 의사소통 행동 비교. 유아특수교육연구, 10, 31-46.

허현숙, 이윤경(2012). 언어학습부진아동의 대화차례 주고받기 및 주제운용 특성. 언어청각장애연구, 17, 66-78.

홍경훈, 김영태(2001). 아동의 의사소통의도 습득에 대한 종단연구. 언어청각장애연구, 6, 17-39. 